b. Crest strongly elevated and surmounted by a horse-shoe shaped ridge; lobe of right clasp greatly expanded, broadest apically..............................horatius.

c. Crest forming a gibbous prickly protuberance; lobe of right clasp greatly expanded, broadest basally..........terentius.

$B$. With or without subapical spots. [Terminal hooks of upper organ separate]; blade of clasps moderately long as compared to the main body. [Costal fold furnished with long pediform bristles, curving at base, and apple-seed shaped scales, but with no thread-tipped tapering scales nor twisted ribbons].

a. With subapical spots. Right clasp with a slightly prominent median denticle; beyond the bend moder-

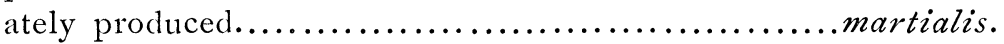

b. Without subapical spots. Right clasp with a somewhat prominent median denticle; beyond the bend much

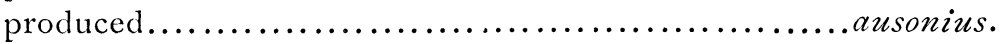

C. No subapical spots. Terminal hooks of upper organ consolidated and stout; blades of clasps very short when compared with the main body. Costal fold furnished with thread-tipped tapering scales or twisted ribbons, but with no long pediform bristles, or apple-seed like scales, or 2-pronged rod-like scales.

a. Of moderate size. Blade of right clasp stout. Costal fold with twisted ribbon-like scales.................... brizo.

b. Of small size. Blade of right clasp slender. Costal fold with thread-tipped tapering scales.................... icelus.

\title{
THE USE OF TWO DOORS IN A TRAP-DOOR SPIDER'S NEST.
}

By George F. AtKinson, Columbia, s. C.

Certain of the species of Nemesia, the habits of which Mr. Moggridge studied, make two trap-doors to their nests, one at the surface of ground at the upper end of the main tube, the other a short distance below at the beginning of a branch tube. Mr. Moggridge supposed the use of the branch and second door was to afford the spider a means of escape when pursued by an enemy. When chased into the main tube, the spider would go into the branch and close the 
door ; the enemy following, and finding the main tube empty, would leave.* In my studies of the nests and food habits of Myrmekiaphila foliata, $\dagger$ I found indications that the main tube was constructed to serve as a gallery for the passage of ants, or other insects, and that the branch was constructed as a real trap, in which the spider awaited the passing of an ant, when it would open the door and catch the insect. The arguments I then advanced, briefly stated, are: ist, the nests then found were all made in places where ants had underground passages, 2 nd, the main tube connected with some of the ant's galleries, $3^{\text {rd }}$, the trap-door at the surface of the ground had the appearance of being little used, and 4 th, one nest had only one door leading into a short tube. This tube opened into the floor of a broad hall of the ant's nest leading into several galleries. Near this broad hall was the opening to the surface of the ground, made by the ants, and through whish the spider probably entered the hall to construct her "branch tube" in the floor.

In May I888, at Chapel Hill, N. C. I found a nest of Myrmekiaphila fo- liata, under conditions which seem to give conclusive evidence that the main tube is intended to entrap unwary insects that they might be "gobbled in" as they pass the door of the branch where the spider remains. The nest was made in a broad foot path, where the clay soil was very hard. I discovered it by seeing the open door. The following day I visited the place with trowel in hand to dig up the spider. I found the door still open. The main tube was about nine inches long, the branch about one inch long and was situated six inches from the surface of the ground. In this I found the spider. The door to the branch was a cork door, while that at the surface of the ground was a wafer door. It appears in cases where the nest is not made in an ant's nest, that the outer door is set open, thus offering an attractive place for insects that are crawling on the surface of the ground in search of food. They enter the main tube, and as they pass the branch, the door is suddenly thrown open, and to their surprise they are taken captive and made a meal of by the cunning spider.

\section{MATING OF SAMIA CYNTHIA IN CAPTIVITY.}

BY CAROLINE G. SOULE, BROOKLINE, MASS.

Last winter I received from Nantucket cocoons of Samia cynthia and on the 8th of May, I888, at I I-30 A. M., a $\delta$ and $\delta$ emerged and crawled up the

* Harvesting Ants and Trap-Door spiders.

$\dagger$ Entomological Americana, Oct. \& Nov.1886. side of my pupa-box at the same time. I removed them to a cage to see if they would mate in captivity.

My cage consists of a shallow flowerpot, seven inches in diameter and nearly full of sand; a circle of heavy cop- 

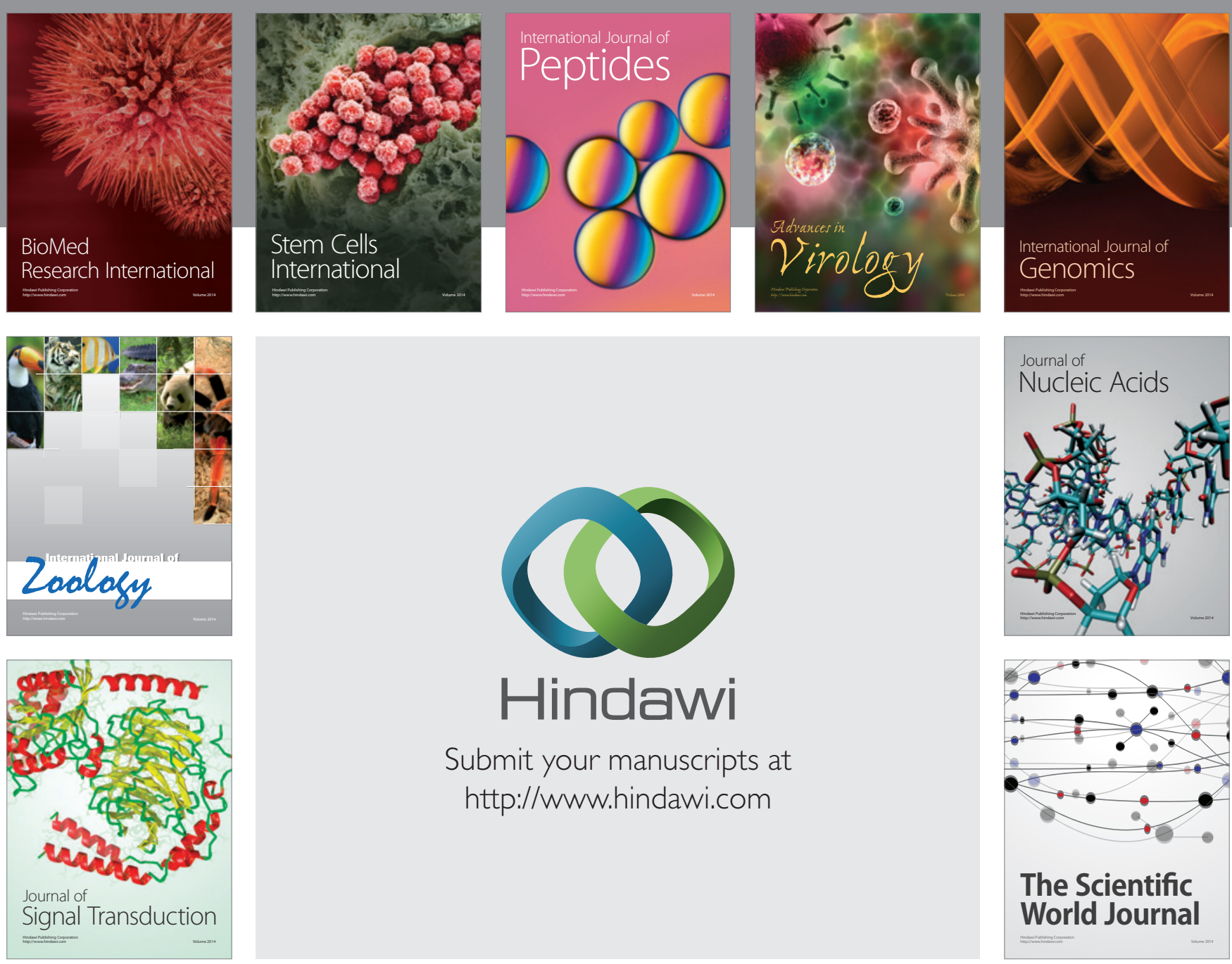

Submit your manuscripts at

http://www.hindawi.com
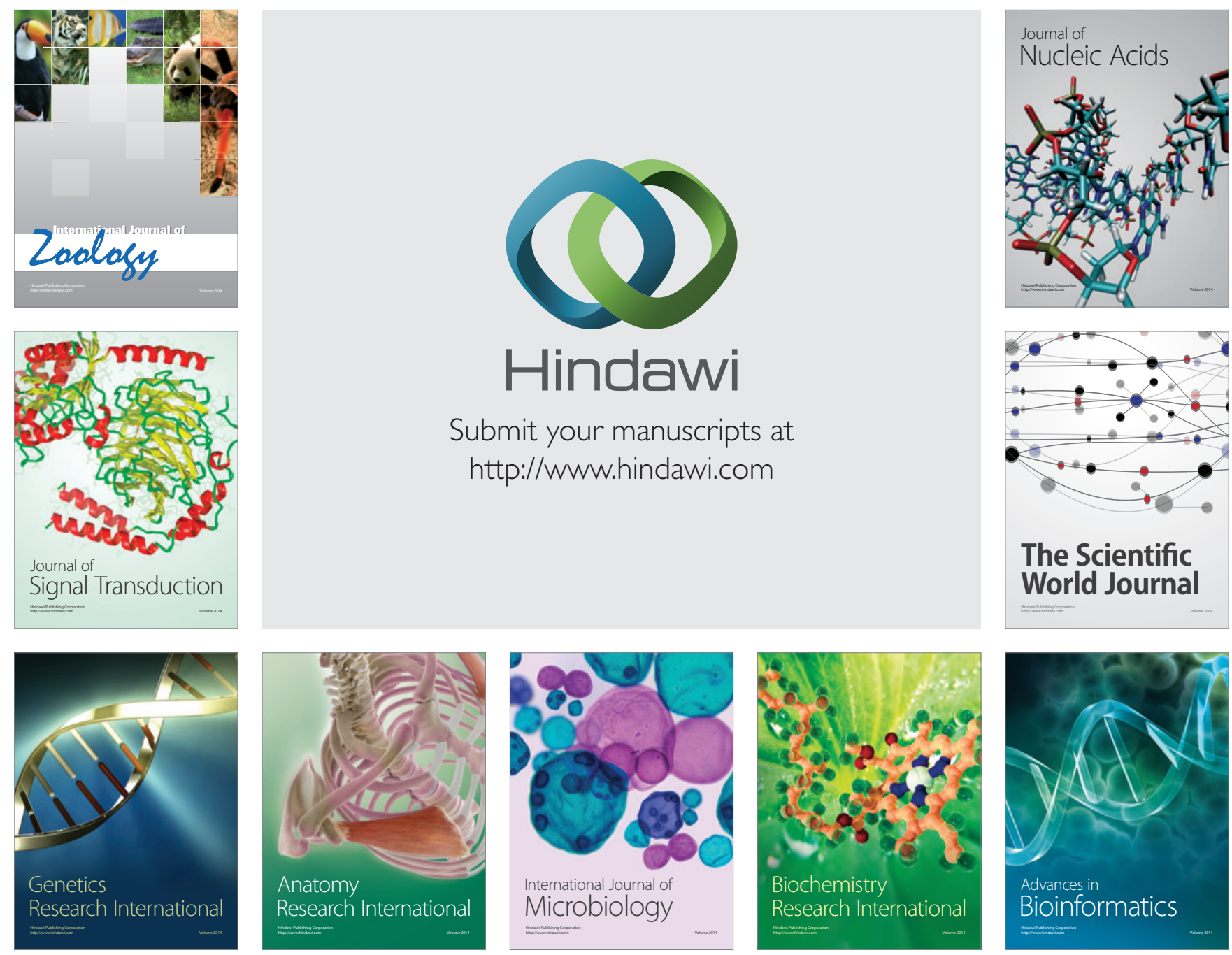

The Scientific World Journal
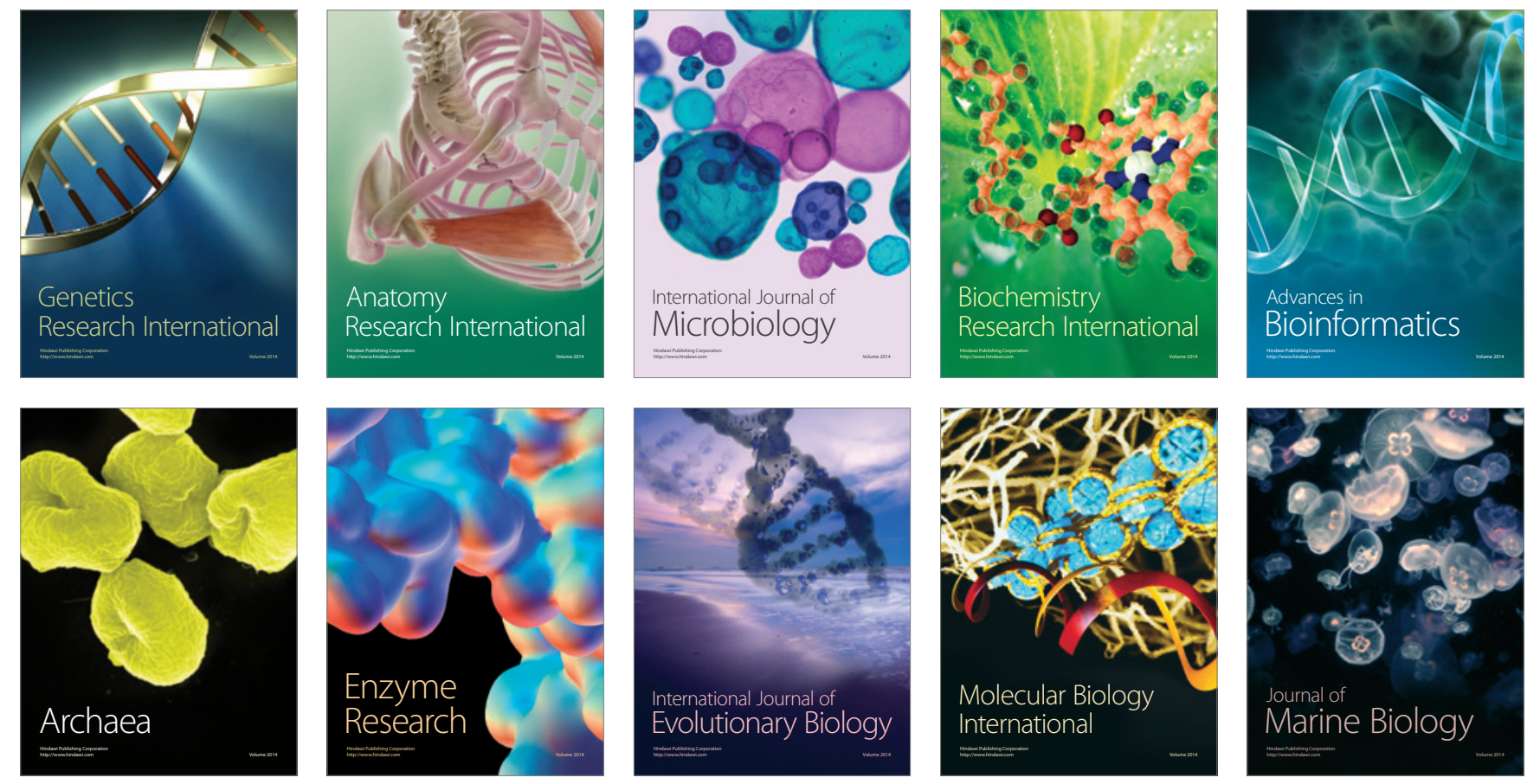